\title{
Farewell, Drop-Out: Hello, Drop-In
}

\author{
Donald B. Black*
}

It is difficult to admit obsolescence after all these years, but that time has come to the school drop-out. No longer does it appear to be as viable a concept in helping to shape meaningful educational policy. Gone, too, will be those many research papers conducted under its aegis. Their passing will be mourned by many.

This is not to say that drop-outs have not contributed to the development of the educational enterprise. On the contrary, this contribution has been sizable. This is not to say, either, that the drop-out as an individual will no longer be of any concern to the educational institution, be it a high school, community college, technological institute or university. At a minimum, his passing represents a very real financial loss to each of them. If the instituttion is crowded with places at a premium, not only is there the loss of one student, but the loss of a second student who was kept out. In excessive numbers, they can cause class sizes to be reduced below enrolment at which it is economical to operate, with all the problems that accompany a decision whether to continue these classes or not. Administratively, drop-outs are nothing but a headache.

From the late 40's and through the early 50's, those concerned with education's role in the use of manpower resources argued that the drop-out represented an item of lost potential to the nation - someone who had gotten into some academic back alley and become lost, and as a result was subsequently relegated to function forever at some fraction of his real capacity. All, and particularly society, were the losers. ${ }^{1}$ The exponents of this position assumed first, that the fruition of human contribution is achieved only when the person and the job are matched at the highest possible level of intellectual capacity. Second, it was assumed that the drop-out or failure ceases any subsequent actions aimed at self-improvement. In other words, having failed in the broadest sense, the individual would not pursue further vocational preparation but rather would opt-out to the work-a-day world where he was destined to remain at that "low level" of employment. In fact, during the early part of this period, this argument

* Dr. Donald B. BLACK is a professor in the Department of Educational Psychology, University of Calgary. 
had a certain validity. The prevailing social mores to a degree supported such an attitude and these same mores were reinforced by the inevitability of military service or static employment in the war effort.

Educators of the period were not happy with this situation. Notwithstanding the stories of what the military did with its manpower, there was the other side of the coin. This showed what could be done when the individuals were assigned to jobs on the basis of talents rather than being given any significant personal choice in the matter. In a peace-time situation and with the return of individual choice, the continuing solution of the educators was to provide for the matching of the individual with his job and all that went with it before he could be side-tracked into a failing enterprise. The relevant maxim was: a matched person will be a happy person.

At this time educators chose to expand counselling services and introduced into the school curriculum the opportunity for low risk vocational experiences through such plans as work experience programmes. Later embellishments ultimately permitted the delay of vocational choice until the last possible moment when a decision had to be made. Yet, for those professions which required university preparation, admission requirements remained highly prescriptive to a degree that the decision to enter one of these professions still had to be made early in the high school programme. While it was possible to scale down one's vocational aspirations during high school, it was impossible to move them upward without paying a heavy penalty in time. For those who could not attend university but possessed the needed potential and prerequisites, their loss to the lower echelons of the labor force was also lamented to the degree that low-cost loans and bursaries appeared in significant numbers for the first time. ${ }^{2}$

By the mid-fifties, the marked success of the veterans in academic and vocational education programmes became readily apparent. This served to confirm previous doubts about the supposedly infallible prescriptive admissions requirements to university and college. Eventually it became generally accepted that adults could successfully "come back", very often even after disastrous records of drop-outs and failure. Manpower potential heretofore presumed lost was clearly retrievable and the rapid expansion of the economy provided the opportunity to prove this. Yet, in the universities, even those ones which pioneered their admission, the adult drop-out (non-matriculated adult) remained very much a novelty and acknowledged success of such persons had little impact on regular and transfer student admissions policies.

The same period saw a gradual change in emphasis of drop-out concern. This was manifested in the form of increasing concern for the individual and what he was doing to himself and his future by dropping-out. The "national concern" perspective still remained, but the point of priority had shifted. ${ }^{3}$ Thus, not only was the drop-out robbing society of his valuable contribution; he was destined to become a burden to society, and to stretch a point, to become one who would have to be supported by the public dole and who would live in squalor. The debilitating effects on the individual's psyche resulting from this dependence were not ignored. At the time, however, some 
found this position highly suspect. In one instance there was an attempt to test this assumption on a national basis. The project failed to gain the necessary financial support because those sitting in judgment on the proposal were so convinced that the outcome would only confirm social failure that they rejected it. To them, the necessary resources of time, effort and money could be better spent in other more promising research endeavours. The proposed study, however, was conducted at a local level in one city and produced totally unanticipated results. ${ }^{4}$ Not only did this small study reveal that the drop-out was doing slightly better than the general population in the acquisition of material comforts, it also showed that three-quarters of the sample had undertaken some kind of formal educational programme during the six years that had passed since dropping-out and the time of the interview.

It was in this same period that the high schools were committed to policies of increasing toughness towards students. School administrators were given support in "forcing out" presumed academic deadwood and pedagogical malingerers, and such actions were widely acclaimed. The Calgary Public School Board's Laggard Policy is but one such example. The defect of this policy was that it made it equally difficult for the laggard student who had seen the error of his ways to find an entry door to resume his education as a young adult with some sense of dignity and for others to accept him as a person starting with a clean slate.

The late 60's and the early 70's have seen further changes in this whole area : university entrance requirements have become increasingly less prescriptive; the Canadian community college as an "open access" institution has come into being; older postsecondary institutions have expanded their programmes and intakes; both secondary and post-secondary education are heavily committed to major extension programmes. Indeed, some high schools who were the first to talk about laggard policies now boast of their drop-in programmes. In other words, and for a host of reasons not discussed here, the position of the schools has been reversed. Instead of being a marked person the drop-out, should he choose to return, now finds opportunities to resume his education awaiting at every turn. The community college alone has probably done more in this regard than any other single institution.

It might also be noted that a current theme in the literature concerns the importance of matching the goals and objectives of the student with those of the institution. It is now recognized that much is to be gained from maintaining the uniqueness of each. 5 The diversity of choice that now exists both between and within types of post-secondary institutions contributes in its own way to improving the situation. With many types of institutions and many different programmes and with eased admission policies, now a student has a greater opportunity to match his interests and goals, even when these have changed, with those of an institution.

It is also a reflection of our changing society that the Age of Aquarius is an age of permissiveness characterized by a rapid decline in significant adult influence over 
adolescent behaviour. The now general reduction of the age of majority to eighteen merely recognizes a social change that has already transpired. It also means that parents are even less likely today to change their offspring's mind once a decision to drop-out has been made. ${ }^{6}$ (The author, as but one harrassed parent, can readily see how it would even be possible for parents to encourage dropping-out if for no other reason than to instill some measure of adolescent responsibility.) Not only are the youth of today more independent; they are likely to be more demanding of the institution to provide what they think is needed in their programmes - relevance is the by-word. Hoffman, in an as yet unpublished master's thesis, found that even in the high schools there is considerable dissatisfaction with the failure of the school curriculum to reflect current social and scientific issues, and with the failure of teachers to act as confidants, i.e., to treat students as equals. ${ }^{7}$ While such dissatisfaction may not be sufficient to cause the student to drop-out, the seeds for future consideration of this act are there. Add to this the growing realization by both parents and educators (but for different reasons) that for some students, dropping-out is the best thing that could happen to them, the conclusion seems obvious. Dropping-out is no longer viewed as the kind of social disaster it once was ; nor should it necessarily be avoided at all costs.

To this point, the discussion has taken a rather cursory and somewhat cavalier look at changing attitudes and philosophies towards the school drop-out. Any student of the Canadian educational scene will not find anything here not readily apparent in the current policies of our educational establishment. Yet, notwithstanding comments to the contrary in the past these same institutions have had very good insights into what kinds of skills are needed to succeed in their programmes. The lowering, or more properly, the relaxing of their admission requirements has meant that, in many cases, these institutions have knowingly been prepared to accept inadequately prepared students, students who will cause the drop-out/failure rates to soar, as the price to be paid to gain those other students who do succeed but who heretofore would never have been admitted.

For some institutions, such as the universities, it is doubtful if their attrition rates have increased significantly since the introduction of eased admission requirements. But for those institutions with "open door" admission, like the community colleges which admit almost solely on the basis of student preference, their attrition numbers cannot help but climb, not just as a result of their admission policies alone but also as more and more of the high school graduates will continue on to some form of post-secondary study. One recent study of drop-outs in an Alberta college showed that 245 of 905 full-time freshman students $(26.7 \%)$ dropped out in the first semester of their programme. In fairness to the particular college concerned, this figure is below that released to the press by the college itself. Surely, then, the drop-out is far from being a thing of the past; a fact that should now be a matter of greater concern than ever before.

This indeed was the position of the author until the analysis of data of two of his graduate students, Mrs. Ellen M. Krempien and Mr. Thomas A. Stott, became available. ${ }^{8}$ Both these Master's students have examined drop-outs in the community college setting 
and the figures cited above are from the Stott thesis. Because of the very newness of the Canadian community college and the lack of this type of empirical study, these two studies had hypotheses developed on the basis of manpower utilization philosophies and justified from earlier American studies. Although limited in scope, these studies have come forward with some rather interesting findings which may have far-reaching implications. Basically, these two researchers have found that the drop-outs from the particular college studied did not conform to the characteristics traditionally found in earlier drop-out studies. When statistically significant differences were found, they are of a degree that would be almost meaningless for application in an operational setting. In fact, some evidence has been collected, particularly in the Stott study, to suggest that, in the traditional areas of academic preparation, drop-outs are not simply as well prepared as those who persist; they are even better prepared. This is important because notwithstanding all other changes, there seems to be no evidence that academic skills, such as reading, are any less valuable today than they were in the past. Similarly, other measures like age, marital status and sex, which in the earlier studies had been found to relate to the likelihood of dropping out, were found here to have no relationship. The only conclusion that can be drawn is that these dropouts left for reasons other than ability. Discouragement is now a factor of such importance that one U.S. investigator has commented that the best way to predict a drop-out is to ask the student if he thinks he will drop out. ${ }^{9}$ After listening to the comments of colleagues in university and technical institute registrars' offices, it seems reasonable to conclude that similar findings would emerge from any study of their drop-outs.

Other noteworthy items of information have come to light from these two studies. First, the number of students who delay their education between high school and postsecondary is increasing. It has been found that 218 of a sample of 475 students from the Krempien study had delayed their educations by at least one year. This would suggest that delay, like dropping-out, no longer has any social stigma attached to it. Certainly, the introduction of youth air fares to Europe, for example, attests to the existence of a sizeable pool of such persons. Another noteworthy finding of the Krempien study, which dealt with full-time students in programmes other than direct university transfer, was that of 85 drop-outs who were later interviewed, 44 indicated that either they intended to or were already continuing their formal education. Equally significant for the administrator was the fact that of the 34 who intended to return, only 11 indicated any intention of returning to the college they had just left. The other ten (of the 44) were already enrolled in other institutions. These findings may explain why Stott found that 175 of his sample of 905 had previous records of dropping-out. Subsequent analysis of this data revealed that of his 242 drop-outs, only 57 had dropped-out before. On the other hand, of those with no record of dropping-out, 185 dropped-out. Tested statistically, this difference could be attributed to chance factors in sampling. One can only conclude that the student with the prior record of drop-out is no more likely to drop-out than one without such record. 
In summary, the drop-out who leaves an institution at some time prior to the completion of his programme will always be part of the educational scene. The same changing social values under which our youth seek independence and demand relevance in their educational undertakings, and as they "do their own thing", would suggest that drop-out rates will continue to rise in the years ahead. The increasing practice in many post-secondary institutions of inviting students to try a programme to see if they like like it before making a firm commitment will also act to inflate artificially even further these attrition rates. But the classification of the drop-out as a person of inferior talents for the programme undertaken is a gross under-simplification and may even be totally erroneous. The classification of the drop-out as a person who will never continue his formal education in some form or another at some future date is also erroneous. This is not to deny that there are drop-outs for whom the traditional characteristic symptoms will apply, but these same symptoms are prevalent among almost as many persisters.

However, for increasing numbers, dropping-out appears to be merely an interruption in their schooling during which some real-life experience is substituted. ${ }^{10}$ The drop-out will still represent an immediate loss to the institution; but the evidence, crude as it is, suggests that when he leaves his place will be taken by someone who had dropped out earlier from perhaps a different institution and now has come back. Under these circumstances, then, the present concept of the drop-out seems a little out-dated and completely pessimistic in format. Should not the effort we now spend in studying dropouts be channelled into more productive channels aiming ultimately at assisting the drop-out to become a drop-in ? As an example of what might be done, counselling services could be made available for the drop-in which are community rather than institution-oriented. Schlossberg, Hoy and Gordon have raised this possibility in a recent paper. ${ }^{11}$ Given the obviously increasing magnitude of the problem at this point in time when there is a tightening budget for auxiliary educational services in all post-secondary institutions, this is one of several positive possibilities that deserves careful examination. One thing is certain. There will never be an absence of a large experimental population of drop-outs cum drop-ins! 


\section{Notes}

1. The writings of Dael Wolfe are typical of this approach. A good example of this author's position is given in his summary of the U.S. Commission on Human Resources and Advanced Training findings presented in, "The Present and Future Demand for Educated Persons", College Admissions, No. 1. (College Entrance Examination Board, 1954), 1-11.

2. For an interesting discussion of this development, see Robert M. Pike, Who Doesn't Get to University and $\mathrm{W}$ by: $A$ Study on Accessibility of Higher Education in Canada. (Ottawa : Association of Universities and Colleges of Canada, 1970), pp. 131-133, et passim.

3. John Porter (e.g., The Vertical Mosaic. University of Toronto Press, 1965) is an excellent example of this period of "joint" concern, i.e., what is good educationally for the individual is good' for the nation which is in turn good for the individual.

4. Vincent, G.B. and Black D.B., "The Drop-Out is Society's Burden : Fact or Fiction?" Canadian Education and Research Digest, 6:4 (December, 1966), 313-330.

5. As an example of this kind of concern, see James S. Coleman, "The Principle of Symmetry in College Choice". Report of the Commission on Tests, II : Briefs. (College Entrance Examination Board. 1970). pp. 19-29.

6. In 1961. Gekoski and Schwartz "Student Mortality and Related Factors", Journal of Educational Research, $54: 5$ (January, 1961), 192-194, reported that 41\% of the interviewed drop-outs indicated that there was nothing that could have been done that would have kept them in school.

7. Gordon Hoffman, A Survey of Senior High Scbool Student Satisfaction-Dissatisfaction in an Alberta Urban Community. (Unpublished Master's Thesis, The University of Calgary, 1971), $165 \mathrm{pp}$.

8. T.A. Stott, Dogmatism and College Drop-Outs. (Unpublished Master's Thesis, The University of Calgary, 1971), $100 \mathrm{pp}$.

Mrs. Krempien's Thesis, A Descriptive Study of Community College Career-Oriented Freshman Drop.Outs, is scheduled for completion in the 1971.72 academic year.

9. Edmond Marks, "Student Perceptions of College Persistence and Intelligence Personality, and Performance Correlates." Journal of Educational Psychology, 58 : 4 (August, 1967), 201-221, 219.

10. Such action has the personal support of Prime Minister Trudeau. See The United Cburch Observer interview with him $(34: 3$, September, 1971, p. 20).

11. Nancy K. Schlossberg, J.C. Hoy, and E.W. Gordon, "Regional Centers for Guidance for Continuing Education." Report of the Commission on Tests: II, Briefs. (College Entrance Examination Board, 1970), 114-124. 